\title{
Towards a Taxonomy of Crowd-Civic Systems
}

\author{
Marta Poblet ${ }^{1}$ \\ ${ }^{1}$ RMIT University, Melbourne, VIC 3000, Australia \\ marta.pobletbalcellarmit.edu.au
}

\begin{abstract}
This paper proposes a preliminary taxonomy of crowd-civic systems developed in a number of areas and geographical contexts. The taxonomy is based on different theoretical models of democracy and their underlying visions of citizenship. While this classification is neither exhaustive nor categorical, it may contribute to discovering connections between theoretical models of democracy and state-of-the-art digital platforms and tools. Framing crowd-civic systems within different models and visions of democracy and citizenship can also shed new light to concepts such as participation or deliberation, as well as to the role of civic technologies in reshaping them.
\end{abstract}

Keywords: crowd-civic systems, civic technologies, crowdsourcing, democracy, law, policy, deliberation, decision-making.

Forthcoming at: Linked Democracy. Foundations, Tools, and Applications (Springer Open). [Subject to modifications: comments welcome].

\section{Introduction}

Crowd-civic systems can be defined as socio-technical systems blending people, digital technologies, and data for civic engagement purposes such as data collection, information management, large-scale deliberation, or decision-making. In recent years, open government initiatives and programs have fostered the design of crowd-civic systems to inform the policy-making process with input from the public (McInnis et al. 2017). This constitutes a step further in the e-government strategies-broadly understood as the electronic delivery of information and services by public entities - that now are universal: since 2014, all 193 UN Member States have national websites in place, even though there is a wide gap between highest and lowest scoring countries and 'substantial variability in the scope of online service delivery' (UN 2014, p. 5-6).

In parallel to these developments in open government, there has been an impressive blossoming of civic technologies across the world. Citizens, grass-root organisations, foundations, NGOs, research centres, and start-ups have contributed to this thriving landscape with an ever-growing number of web-based services, platforms and apps with varied purposes and functionalities. Despite the heterogeneity of their goals, designs, contextual applications, and users, crowd-civic systems epitomise both 
the potential and the limits of digital democracy as 'the practice of democracy using digital tools and technologies' (Simon et al. 2017: 11).

In this paper we propose a preliminary taxonomy of crowd-civic systems based on different models of democracy and conceptions of citizenship. We suggest that the tools included in the taxonomy are related to some particular model of democracy (liberal, civic-republican, developmental, deliberative, and epistemic) and conception of citizenship (noted as 'scope'). At the same time, they contribute to actualise these models by opening up new civic practices and, ultimately, suggest redefined concepts of citizenship, participation, representation, or deliberation.

\section{Proposed Taxonomy}

Crowd-civic system designers, developers, and users may not explicitly link their digital tools to any conceptual model of democracy and citizenship. Yet, it is possible to connect present crowd-civic systems with different visions of citizenship derived from liberal, republican, deliberative, and epistemic theories of democracy. Highlighting these linkages can help to elucidate the current discussions around 'digital citizenship' that are taking place in a number of academic disciplines (political sciences, sociology, media and communication studies, etc.). As Engin Isin and Evelyn Ruppert have succinctly argued, "any attempt at theorizing 'digital citizens' ought to begin with the historical figure of the citizen before even shifting focus to the digital" (2015: 19).

Table 1 below frames a subset of 130 crowd-civic systems (52 of them open source) within different political theories of democracy and their related visions of citizenship. The categorisation of the models (liberal, republican, developmental, and deliberative) draws from previous work by Geoffrey Stokes (2002). We also have added the 'epistemic' model (together with the deliberative one) since some of the crowd-civic systems (e.g. constitution-drafting platforms) combine mass-scale deliberation functionalities with the aggregation of structured ideas, issues, or contents via microtasking (for example, they invite their users not only to discuss the pros and cons of a suggested article, but also to draft a new version of it).

The suggested taxonomy is far from exhaustive. To be sure, an extended survey would certainly help to discover a much larger number of tools currently in use. It is not categorical or clear-cut either, as a number of tools may be linked to more than one model and/or scope. If that is the case, then we consider the core functionality of the tool to determine its most adequate position in the table 1.

We have followed two basic criteria when including digital tools in Table 1: conceptual and technical. First, we have included civic, grass-roots, foundations, research, or start-up initiatives aimed at citizens' participation, as opposed to a number of local, state, and national government-supported consultation platforms (e.g. the ones by states such as South Australia (YourSAy), ${ }^{1}$ or by local councils in Mexico

\footnotetext{
${ }^{1}$ https://yoursay.sa.gov.au/
} 
City, Barcelona or Madrid (Constitución CDMX, ${ }^{2}$ Decidim Barcelona, ${ }^{3}$ and Decide Madrid, ${ }^{4}$ respectively) to name just a few. Likewise, initiatives by parliaments such as Wikilegis ${ }^{5}$ in Brazil or Mi Senado in Colombia ${ }^{6}$ have been left out of our scope. Nevertheless, it is important to note that governments at different levels have currently deployed some of these platforms included in the table. For example, a number of Spanish municipalities, including Barcelona and Madrid, use the open source platform Consul, while some others have opted for Civiciti, which is not open source but offers a free version to small municipalities.

Second, our taxonomy includes tools that leverage some form of crowdsourcing. In this particular context, crowdsourcing methods can consist of outsourcing input information from the general public-e.g. collecting data about candidate representatives and political parties_-, collecting ideas, comments, and petitions in a particular area, or designing more elaborated forms of microtasking where participants are requested to complete a specific task-e.g. reporting incidents for election monitoring tasks (with Ushahidi), or providing their version of an article in a proposal for a new legislation, bill, or constitution (e.g. LaConstituciondeTodos.cl or unanovanonstitucio.cat).

\footnotetext{
${ }^{2}$ https://www.cdmx.gob.mx/constitucion

${ }^{3} \mathrm{https}: / /$ www.decidim.barcelona/

${ }^{4} \mathrm{https}: / /$ www.decidemadrid.es/

${ }^{5} \mathrm{https} / / /$ beta.edemocracia.camara.leg.br/wikilegis

6 http://www.senado.gov.co/historia/item/26548-senado-lanza-app-mi-senado-un-paso-mashacia-la-modernidad-y-la-transparencia
} 
Table 1. Crowd-civic systems

\begin{tabular}{|c|c|c|c|c|c|}
\hline Vision & Liberal & & Republican/monitorial & Developmental & Deliberative/epistemic \\
\hline \multirow[t]{43}{*}{ Scope } & Access & Vote & Monitor & Engage/network & Deliberate/design \\
\hline & Americadecoded & AgoraVote* & Abgeordnetenwatch.de & Aavaz.org & All Our Ideas \\
\hline & Changepolitics & BallotBin & Alaveteli.org* & Brigade & Argunet* \\
\hline & Civi* & BoardRoom & Askthem.io* & Change.org & Assembl* \\
\hline & ClearGov & Easypolls & Dailwatch.ie & Citizinvestor.com & AvoinMinisterio* \\
\hline & Congress app & Electionbuddy & Del Dicho al Hecho* & Cityflag & Carneades* \\
\hline & DemocraticDashboard & $\mathrm{e}-\mathrm{Vox} *$ & Elections* & Citysourced.com & Civiciti \\
\hline & $\mathrm{DKAN}^{*}$ & FollowMyVote* & Elteuparlament.cat & Civinomics & Cohere $^{*}$ \\
\hline & Digital Democracy & Helios Voting* & FragDenStaat.de* & Communityplanit.org & Collaboratorium \\
\hline & Everypolitician* & nVotes & GovTrack & Ethelo.org & Common Ground for Action \\
\hline & Followthemoney & OpaVote & Issues* & Frankfurt Gestalten* & Compendium* \\
\hline & Intuitive voting & OpenVoters* & Nosdeputes.fr* & Fixmystreet.org* & Consider.it \\
\hline & MapIt* & Simply Voting & Nouabook.ma & GlobalCitizen.org & Constitucio.cat \\
\hline & Okffi* & TrustTheVote & Marsad.tn & Neighbor.ly & Consul* \\
\hline & OpenAustralia* & Turbovote & Meinparlament.at & Neighborland.com & Dastoorikurdistan.org \\
\hline & Opencongress & Vooter & Mobadara-rif.ma & OurSay.com & Debate.org \\
\hline & Openstates & & OpenDialog & Petitions* & Debategraph.org \\
\hline & PartyofLincoln & & OpenParlamento* & Represent & DebateHub* \\
\hline & Politicalpartytime & & OpenPolitici* & Seeclickfix.com & Debatepedia.com \\
\hline & Politomix & & Politikercheck.lu & & Debatewise.org \\
\hline & SayIt* & & Pombola* & & Deliberatorium \\
\hline & They Vote For You* & & Questionnezvoselus.org & & DemocracyOS* \\
\hline & VoiSieteQui* & & Right to Know* & & Discourse* \\
\hline & The Voting App & & Sahana* & & EngagementHQ \\
\hline & Yoquierosaber & & Theyworkforyou.com* & & LaConstituciondetodos.cl \\
\hline & YourNextRepresentative* & & Ushahidi* & & Loomio \\
\hline & & & Votewatch.eu & & LiquidFeedback* \\
\hline & & & Vouliwatch.gr & & LiteMap* \\
\hline & & & Whatdotheyknow.com* & & Madison* \\
\hline & & & Writeinpublic.com* & & Mindhive \\
\hline & & & Writetothem.com* & & Objective $8 *$ \\
\hline & & & & & Opentownhall.com \\
\hline & & & & & Parlement\&Citoyens \\
\hline & & & & & PolemicTweet* \\
\hline & & & & & Pol.is* \\
\hline & & & & & PyBossa* \\
\hline & & & & & PopVox \\
\hline & & & & & Reddit \\
\hline & & & & & RegulationRoom \\
\hline & & & & & Unanovaconstitucio.cat \\
\hline & & & & & Whysaurus.com* \\
\hline & & & & & YourPriorities \\
\hline & & & & & UNU.ai \\
\hline
\end{tabular}

* The system is open source. 


\section{$3 \quad$ Models and scopes}

How can we synthesize these different models of democracy and visions of citizenship (or 'scopes') in Table 1? A cautionary note is required here, for this synthesis is a highly simplified version of models and conceptualisations that democracy theorists, coming from different philosophical traditions, have been elaborating over the past decades. We are also mindful of Mark Warren's cautioning words: "democratic theorists usually think in terms of "models of democracy"-a strategy that encourages us to center our thinking on an ideal typical feature of democracy, such as deliberation or elections, and then to overextend the claims for that feature (Warren 2017: 39). Our synthesis of models should therefore be read through Warren's lens.

\subsection{Liberal model}

Under a liberal, minimalist vision of citizenship, citizens are basically expected to vote in elections, so that access to information (and limited deliberation) is instrumental to that purpose. Hence, when it comes to the scope of the liberal vision, we consider these two dimensions: access and vote. 'Access' includes tools that aim at collecting and structuring the data and information that citizens need to know to cast informed votes in political elections. These data can be sourced from open datasets, if available, or crowdsourced from the public. 'Vote' contains those tools whose core functionality (while not necessarily focusing on political processes) is to facilitate the design of and implementation of online elections, polls, or surveys.

\subsection{Republican/Monitory models}

Republicanism constitutes a long and rich tradition in political philosophy, inspiring different conceptions of citizenship over time (e.g. Held 2006). From a republican perspective, the protection of the 'public interest' or the 'common good' generally demands greater involvement of citizens in politics, and hence a more proactive role to deter arbitrary abuses of power. As Philip Pettit - one of the main proponents of contemporary 'civic republicanism'-summarised, the protection of republican freedoms and the common interest relies 'on the existence of an active, concerned citizenry who invigilate the exercise of government power, challenge its abuses and seek office where necessary' (Pettit 2003). In this same vein, Frank Lovett points out that 'through collective political action, citizens can bring instances of domination to public attention; they can support laws and policies that would expand republican freedom; and they can do their part in defending republican institutions when called upon to do so' (2017).

This vision also resonates with John Keane's notion of 'monitory democracy', which he defines a as "'post-Westminster' form of democracy in which powermonitoring and power-controlling devices have begun to extend sidewards and downwards through the whole political order' (2009). The list of monitory bodies is 
extensive and includes, for example, 'public integrity commissions, judicial activism, local courts, workplace tribunals, consensus conferences, parliaments for minorities, public interest litigation, citizens' juries, citizens' assemblies, independent public inquiries, think-tanks, experts' reports, participatory budgeting, vigils, 'blogging' and other novel forms of media scrutiny' (2009). Although crowd-civic systems are out of the scope of Keane's work, the tools we list in Table 1 under the 'republican' vision are monitorial in Keane's sense: tools that enable citizens to ask questions to their representatives, monitor, report and/or map people and political processes (e.g. elections, parliamentary activity, deployment of policies, etc.).

\subsection{Developmental model}

In the developmental vision of democracy, the proactive of role of citizens is not restricted to the political realm. Rather, citizens adopt an expansive, far-reaching commitment to enhance the conditions of their (online and offline) communities. In other words, there is a high expectation that citizens will be able to contribute to the betterment of their polity at any of its levels (local, national, or supranational).

This broader consciousness of community and its collective concerns expands to areas where only very recently the Web 2.0 has enabled citizens' involvement at a large scale (for example disaster management or citizen science) ${ }^{7}$. The crowd-civic systems considered under this vision aim at engaging citizens to network (e.g. Brigade), participate in detecting community issues and improving the local environment (e.g. CityFlag, CitySourced, FixMyStreet, Neighbor.ly, SeeClickFix) or in supporting both local and global petitions and campaigns (e.g. Aavaz.org, Change.org, GlobalCitizen.org).

\subsection{Deliberative/epistemic models}

Deliberative democrats situate deliberation as the underpinning principle of their theories. Although an oceanic literature has provided multiple definitions and principles over the past two decades, John Dryzek and Simon Niemeyer (2010) have outlined what they consider to be the essential components that constitute deliberative systems. Thus, deliberation is supposed to be: (i) authentic (debate, discussion, or dialogue in non-coercive ways, encouraging reflection and accommodation of diverse views; (ii) inclusive (all 'affected actors' may participate), and (iii): consequential (can determine outcomes such as laws, policies and decisions). Public deliberation by 'free and equal' citizens provides legitimation for political decision-making, therefore, justifications for proposed decisions, policies and laws need to be publicly given and debated to inform the voting public.

Epistemic models have developed in parallel to these visions and the body of literature is not less impressive. Melissa Schwartzberg (2015: 187-88) contends that 'epistemic democracy does not position itself as an alternative to deliberative democ-

\footnotetext{
${ }^{7}$ We have surveyed a number of digital tools and platforms for crowdsourced disaster management in Poblet et al. (2017).
} 
racy but instead generally resituates deliberation as being instrumental to meet the aim of good, or correct, decision making'. Similarly, Hélène Landemore argues that 'epistemic democracy is both a subset of deliberative democracy and goes beyond it because it includes things that deliberative democracy doesn't necessarily include' (Knight et al. 2016, 142). According to Landemore, the epistemic models aim 'to emphasize the knowledge-producing properties of democratic institutions and procedures' (Knight et al. 2016: 141). An epistemic vision of democracy, therefore, is consistent with citizens playing an active role in producing contextually relevant knowledge in collaborative ways (e.g. making proposals, drafting of legal texts, etc.).

From this perspective, crowd-civic systems in the last column of Table 1 enable the emergence of collective knowledge about topics under discussion. By leveraging different design features that facilitate interaction, debate, and content creation, these systems aim at overcoming the limits of mainstream social media as flagged by a number of studies (e.g. Gurkan et al. 2010, Klein 2015, Iandoli et al. 2016, 2017). For example, as Mark Klein (2015) has aptly pointed out, social media predominance of time-centric discussions (where contents are organised based on the time they are posted) tend to produce low signal-to-noise ratios, insular ideation, balkanisation, non-comprehensive coverage, etc. that may hinder functional deliberation.

To address these issues, a number of crowd-civic systems have incorporated the alternative designs to time-centric systems that Klein (2015) identifies: (i) questioncentric systems (Pol.is, UNU.ai) (ii) topic-centric systems (e.g. All Our Ideas, Cohere); (iii) debate-centric (e.g. Consider.it, Common Ground for Action, DebateGraph, Debatepedia); (iv) argument-centric systems, (e.g. Argunet, Carneades, Deliberatorium, Whysaurus). In addition to that, we can also refer to some systems as 'microtask-centric', as they invite users to complete a task (PyBossa) or draft/amend a small text (e.g. Dastoorikurdistan.org, LaConstitutiondeTodos.cl, Unanovaconstitucio.cat). Some tools are also 'internally sequential', that is, they provide a voting system once the deliberation phase concludes (e.g. Assembl, Consul, Civiciti, DemocracyOS). Whether they are also externally 'sequential' in Dryzek and Niemeyer's sense (determining outcomes such as laws, policies and decisions) (Dryzek and Niemeyer 2010), or externally 'aligned' in Josiah Ober's one (facilitating a seamless transition from decision-making to implementation of decisions) (Ober 2008) can only depend on institutional commitments, arrangements, and prodecures that are external to the platforms.

\section{Conclusion}

Much has been written about the role of social media as spaces for accessing information, sharing contents, and engaging in public conversation. Facebook or Twitter are inevitable channels for anyone willing to engage in large-scale conversations, foster mobilisation, and promote civic engagement. Yet, the shortcomings of social media when it comes to facilitating structured and systematic debates have also been pointed out. 
In recent years, civic technologies have emerged to equip citizens with more tailored tools for an ever-expanding range of initiatives, both locally and globally. The dynamic interplay between people, technologies, and multiple sources of data is paving the way for new practices of participation, deliberation, and representation in different domains (e.g. Casanovas et al. 2017). Ultimately, it may help to redefine the ways that we conceive the exercise of citizenship in contemporary democracies. In this paper we have outlined a preliminary taxonomy of crowd-civic systems that frames a subset of online platforms and apps within different models of democracy and conceptions of citizenship. By providing such a framework we also try to understand the scope of these tools and their relative position in a growing civic-technology ecosystem. In doing so, we also expect to contribute to a multidisciplinary dialogue that enriches democratic theory and practice.

\section{References}

1. Casanovas, P., Mendelson, D., \& Poblet, M. (2017). A Linked Democracy Approach for Regulating Public Health Data. Health and Technology, 1-19.

2. Dryzek, J. S., \& Niemeyer, S. (2010). Deliberative Turns. In J. Dryzek (ed.). Foundations and Frontiers of Deliberative Governance, Oxford Scholarship Online, 3-17.

3. Gürkan, A., Iandoli, L., Klein, M., \& Zollo, G. (2010). Mediating debate through on-line large-scale argumentation: Evidence from the field. Information Sciences, 180(19): 36863702 .

4. Held, D. (2006). Models of democracy. Cambridge, UK: Polity Press.

5. Iandoli, L., Quinto, I., Spada, P., Klein, M., \& Calabretta, R. (2017). Supporting argumentation in online political debate: Evidence from an experiment of collective deliberation. New Media \& Society, https://doi.org/10.1177/1461444817691509.

6. Iandoli, L., Quinto, I., De Liddo, A., \& Buckingham Shum, S. (2016). On online collaboration and construction of shared knowledge: Assessing mediation capability in computer supported argument visualization tools. Journal of the Association for Information Science and Technology, 67(5), 1052-1067.

7. Isin, E.F., \& Ruppert, E.S. (2015). Being Digital Citizens. London: Rowman \& Littlefield International.

8. Keane, J. (2009). The life and death of democracy. London: Simon and Schuster.

9. Klein, M. (2015). A Critical Review of Crowd-Scale Online Deliberation Technologies (September 4, 2015). MIT Sloan Research Paper No. 5143-15. Available at SSRN: https://ssrn.com/abstract=2658811 or http://dx.doi.org/10.2139/ssrn.2658811

10. Knight, J., Landemore, H., Urbinati, N., \& Viehoff, D. (2016). Roundtable on Epistemic Democracy and Its Critics. Critical Review, 28(2), 137-170.

11. Lovett, F. (2017) "Republicanism", The Stanford Encyclopedia of Philosophy (Spring 2017 Edition), E. N. Zalta (ed.), https://plato.stanford.edu/archives/spr2017/entries/republicanism.

12. McInnis, B., Centivany, A., Kim, J., Poblet, M., Levy, K., \& Leshed, G. (2017). Crowdsourcing Law and Policy: A Design-Thinking Approach to Crowd-Civic Systems. In Companion of the 2017 ACM Conference on Computer Supported Cooperative Work and Social Computing.

13. Ober, J. (2008). Democracy and Knowledge. Princeton: Princeton University Press. 
14. Pettit, P. (2003) "Republicanism", The Stanford Encyclopedia of Philosophy (Spring 2003 Edition), E. N. Zalta https://plato.stanford.edu/archives/spr2003/entries/republicanism/.

15. Poblet, M., García-Cuesta, E. \& Casanovas, P. (2017). Information Systems Frontiers: 117. doi:10.1007/s10796-017-9734-6

16. Simon, J., Bass, T., Boelman, V., \& Mulgan, G. (2017). Digital Democracy. Nesta, UK.

17. Stokes, G. (2002). Democracy and citizenship. In A. Carter and G. Stokes (eds.) Democratic theory today. Polity Press, Cambridge: 23-51.

18. Schwartzberg, M. (2015). Epistemic Democracy and its Challenges. Annual Review of Political Science 18: 187-203.

19. United Nations. 2014. UN e-government survey 2014: E-government for the future we want. Available from http://publicadministration.un.org/egovkb/en-us/Reports/UN-EGovernment-Survey-2014

20. Warren, M. E. (2017). A problem-based approach to democratic theory. American Political Science Review, 111(1): 39-53. 